\title{
Molecular Weight Enhancement of Liquid Crystalline Polyester by Shearing
}

\author{
Byung-Wook Jo, ${ }^{\dagger}$ Soo-Kyung ChOI, Jae-Kon ChoI,* Joon-Seop Kim,* \\ Jin-Hae CHANG, ${ }^{* *}$ and Jung-Il JIN ${ }^{* * *}$ \\ Department of Chemical Engineering, Chosun University, Kwangju 501-759, Korea \\ * Department of Polymer Science \& Engineering, Chosun University, \\ Kwangju 501-759, Korea \\ ** Department of Polymer Science \& Engineering, Kum-Oh University of Technology, \\ Kumi 730-701, Korea \\ *** Department of Chemistry, Korea University, Seoul 136-701, Korea
}

(Received August 26, 1996)

\begin{abstract}
Molecular weight enhancement by shearing of a liquid crystalline polymer was studied. The modification of Agarwal and Khakhar's reactor was used as a shear induced reactor for polymerization. It was found that shearing a reaction solution induces an increase in the number of growing liquid crystalline polyester molecules with the proper orientation to react with each other, and thus increases the molecular weight of the polymer. The enhancement was found to increase with increasing shear rates.

KEY WORDS Shear / Molecular Weight Enhancement / Orientation / Liquid Crystalline Polymer /
\end{abstract}

Rigid rod-like high molecular weight polymers are of considerable importance in the production of ultra high strength/modulus materials because they show liquid crystalline behavior in certain solutions or temperature range. Such properties originate from the easy orientation of the rigid molecules during processing, due to the rigidity and the high aspect ratio of the mesogens. Orientation of molecules may also play an important role in the polymerization of rigid rod-like mesogen molecules.

Some polymerization procedures may be diffusion controlled, and diffusion of the growing molecules decreases as the polymerization proceeds. Several diffusion controlled, step-growth polymerization methods for rod-like polymers have been reported. ${ }^{1-4}$ The polymerizations generally require near-parallel orientation of the molecules to enhance the molecular weights of resulting polymers. ${ }^{3}$ After an initial period of time, in which the rate of the polymerization is relatively fast, slow rotational diffusion of the molecules is found to limit the rate of reaction; thus, the molecular weight of polymer increases very siowly with time. ${ }^{4}$ Doi and Edwards showed that the steady-state orientation distribution under a shear flow depends on only one parameter if the rotational diffusivity is only a function of the shear rate $(\dot{\gamma})$, i.e., $\dot{\gamma} / D_{\text {rot }}$, where $D_{\text {rot }}$ is the rotational diffiusion constant. ${ }^{5}$ In the semidilute regime, $D_{\text {rot }}$ decreases sharply with the length of a growing polymer molecule, i.e., $D_{\text {rot }} \approx L^{-7}$, and the proximity of reactive end groups and near parallel alignment of molecules become difficult. Vigorous stirring during such a polymerization is found to be necessary to obtain high molecular weights, ${ }^{6,7}$ and the type of agitator used affects the molecular weight.

In this work we have conducted a study of the effect of a shear flow on the polymerization on the basis of polycondensation between acid chloride and rigid rod

\footnotetext{
${ }^{\dagger}$ To whom all correspondence should be addressed.
}

mesogenic molecules, having a substituent on a phenylene ring. A polymer with a flexible methylene spacer was also synthesized in a shear flow to investigate the effect of chain flexibility on the polymerization rate.

\section{EXPERIMENTAL}

\section{Shear Induced Reactor}

The reactors used in this experiment are shown in Figure 1, which are the modification of Agarwal and Khakhar's. ${ }^{4}$ Reactor I was designed as an ordinary reactor for polycondensation equipped with a mixer, a thermocouple, a temperature controlling unit and a gas inlet tube. Reactor II has an additional rotor operated by a high torque motor to give various shear rates to the polymerizing reactants.

\section{Polymerization}

The polymerization was carried out according to the following reactions ${ }^{8,9}$ in the two reactor system. The solvent used in the polymerization was a mixture of 1,1,2,2-tetrachloroethane (TCE) and pyridine $(8 / 2, \mathrm{w} / \mathrm{w})$. A diol compound was dissolved in the solvent mixture to yield a solution containing 0.05 mole of diol. The solution was poured into reactor $\mathrm{I}$, and was cooled down to $5^{\circ} \mathrm{C}$. 0.051 moles of terephthaloyl chloride were dissolved in the same solvent mixture and was added to the first solution in the reactor I. Stirring of the solution was then started by means of a high-speed stirrer. In $c a$. $10 \mathrm{~s}$, the temperature of the reaction mixture rose to $c a$. $20^{\circ} \mathrm{C}$; it then dropped rapidly down to $10^{\circ} \mathrm{C}$ in $1 \mathrm{~min}$ under cooling. After that, the temperature of reactors I and II was increased to $60 \pm 2{ }^{\circ} \mathrm{C}$. A part of polymerizing mixture was transferred from reactor I to reactor II. After the stirrer of the reactor I was stopped, the rotor of the reactor II was started at the desired speed. A very brief reaction route and sample designation are shown in the scheme below. 


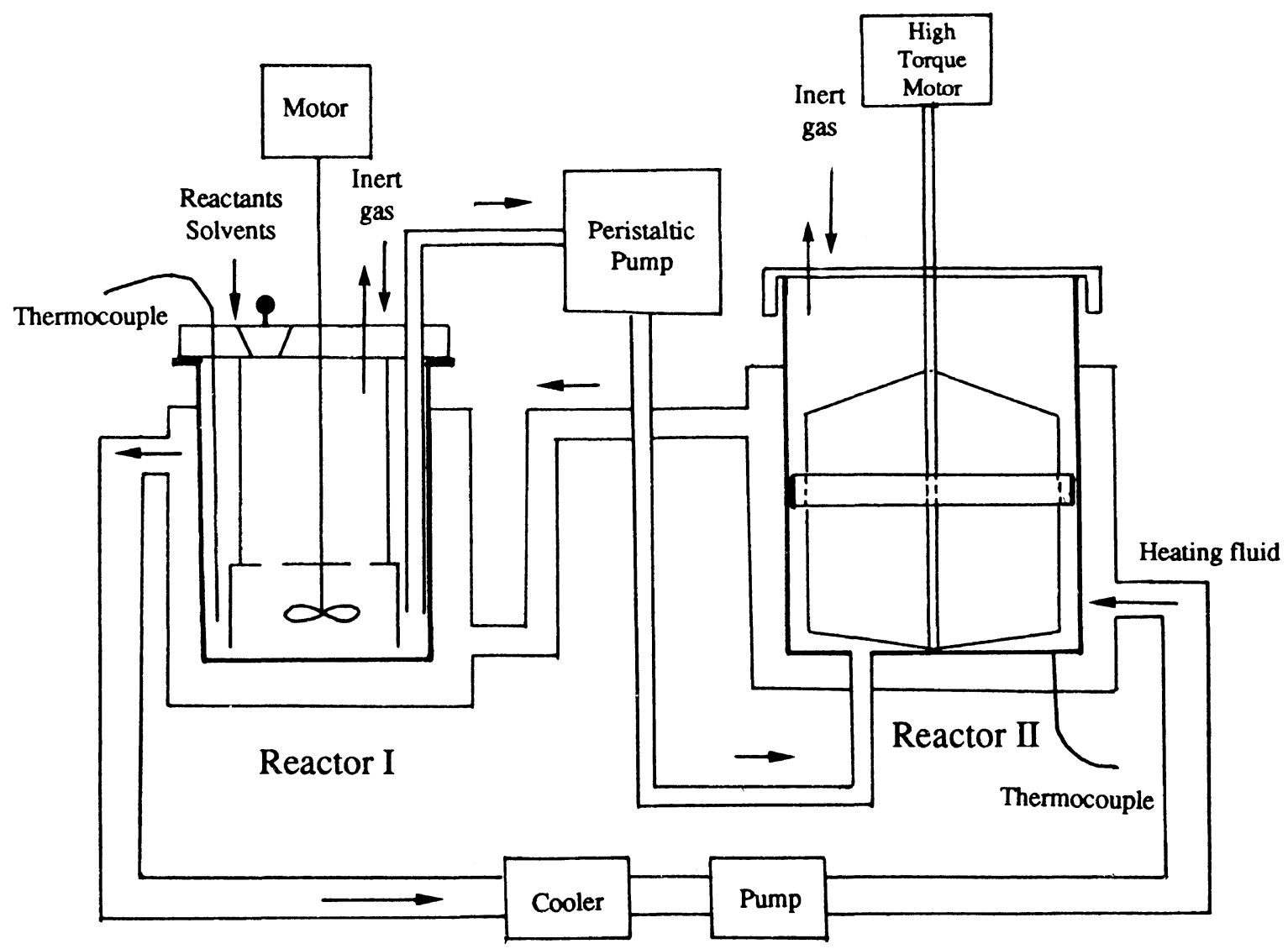

Figure 1. Schematic diagram of the polymerization apparatus.

${ }_{n} \stackrel{\mathrm{O}}{\mathrm{ClC}}-\stackrel{\mathrm{O}}{\|}-\mathrm{CCl}+{ }^{\mathrm{C}} \mathrm{HO}-\mathrm{R}-\mathrm{OH} \stackrel{\text { TCE/pyridine }}{\longrightarrow}$<smiles>CC(=O)c1ccc(C(=O)OOPO[14CH3])cc1</smiles>

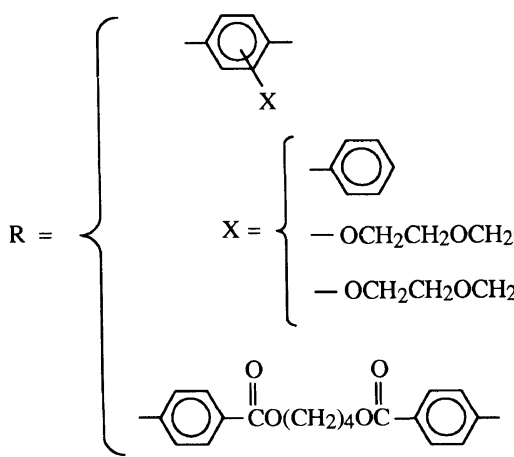

polymer I

polymer II

polymer III

polymer IV

The kinetics of polymerization were studied by quenching the reaction with methanol at certain times. The polymers were dried at $90^{\circ} \mathrm{C}$ under vacuum for $24 \mathrm{~h}$. The inherent viscosities of the polymers in a mixture of TCE and phenol $(7 / 3, \mathrm{w} / \mathrm{w})$ were measured to obtain relative molecular weights. All the polymers revealed liquid crystalline behavior in their melts as identified previously. ${ }^{8,9}$

\section{RESULTS AND DISCUSSION}

The inherent viscosities of rigid rod-like polymers, i.e.,

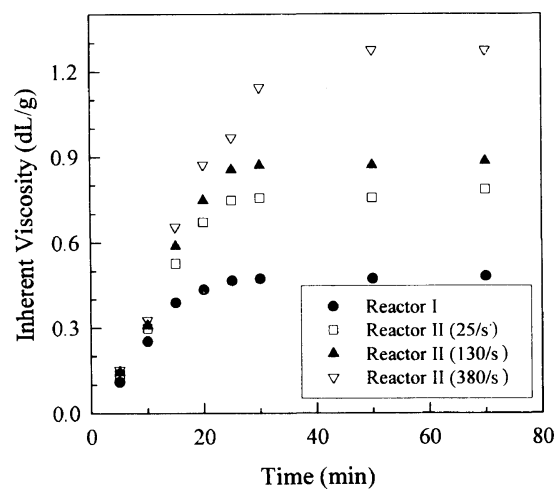

Figure 2. Inherent viscosities of polymer I in reactors I and II with time at different shear rates.

polymers I-IV, obtained from the reactors I and II for different shear rates are presented in Figures $2-5$ as a function of reaction time. Each data point is obtained from a different experiment. As shown in the figures, the inherent viscosities of the polymers initially increase significantly and then reach at plateau values. Doi and Edwards suggested that the rotational and translational diffusivities of the polymer decrease dramatically with increasing the size of molecules, leading to a diffusion controlled, slow reaction rate. ${ }^{10}$ This accounts for the leveling-off of the viscosity as a function of time.

The polymers obtained from reactor II show higher viscosities than those obtained from reactor I, and also higher molecular weights with increasing the shear rate. Agarwal and Khakhar reported that if the shear rate is high enough $\left(\dot{\gamma} / D_{\text {rot }}>1\right)$, and the sizes of the molecules 


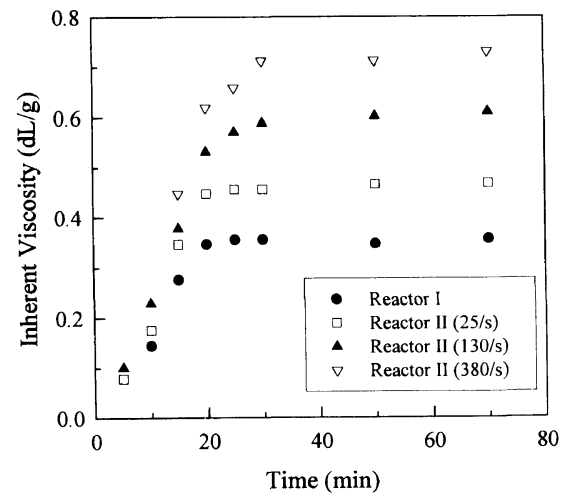

Figure 3. Inherent viscosities of polymer II in reactors I and II with time at different shear rates.

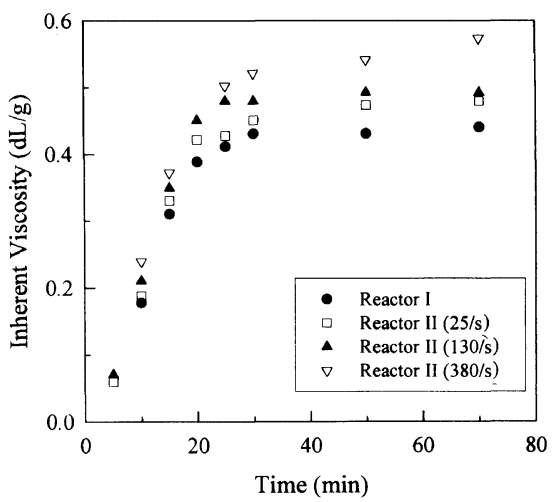

Figure 4. Inherent viscosities of polymer III in reactors I and II with time at different shear rates.

are large enough, significant orientation of the molecules occurs locally. ${ }^{3}$ It increases the number of pairs of molecules with orientation suitable for reaction and thus increases the reaction rate. Furthermore, the viscosity of the polymer increases with increasing the shear rate. More detailed interpretation of the data obtained from each sample in the present work is given below.

In Figure 2 the inherent viscosities of the polymer I (having a phenyl group as a substituent on the phenylene ring) solution are shown as a function of time. It was found that the inherent viscosity of the polymer I solution increases dramatically with increasing shear rate from $0.47 \mathrm{dL} \mathrm{g}^{-1}$ or zero shear rate to $1.23 \mathrm{dL} \mathrm{g}^{-1}$ for $380 \mathrm{~s}^{-1}$. The inherent viscosities of the polymer II and III (having long flexible side chains) are shown as a function of time in Figures 3 and 4 . The increases in the viscosity values in the plateau region are not large, compared with that of the polymer I. It seems likely that the bulky, long flexible side substituents in polymers II and III make molecular orientation difficult even at a high shear rate; thus, the viscosities of polymers II and III are lower than those of polymer I. When one compares the inherent viscosities of polymer II with those of polymer III, it is found that the viscosities of polymer II are higher than those of polymer III under the same reaction conditions. This may be due to the longer flexible substituent on the main chain of the rigid rod molecules, i.e., polymer III, which makes molecular orientation of the polymer chain more difficult. The longer flexible side chain may also cause more steric hindrance for the end groups of the growing polymer

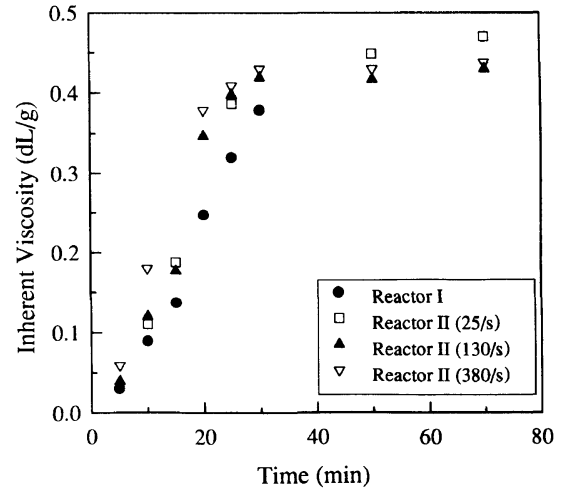

Figure 5. Inherent viscosities of polymer IV in reactors I and II with time at different shear rates.

Table I. Inherent viscosities (i.v.) of polymers I and II with different shearing histories

\begin{tabular}{|c|c|c|c|c|c|}
\hline \multirow{2}{*}{ Sample } & \multicolumn{3}{|c|}{ Shear rate $/ \mathrm{s}^{-1}$} & \multicolumn{2}{|c|}{ i.v./ $\mathrm{dL} \mathrm{g}^{-1}$} \\
\hline & $1-5 \mathrm{~min}$ & $5-10 \mathrm{~min}$ & $10-15 \mathrm{~min}$ & Polymer I & Polymer II \\
\hline A & 25 & 130 & 380 & 0.97 & 0.69 \\
\hline B & 25 & 380 & 380 & 0.98 & 0.67 \\
\hline $\mathrm{C}$ & 380 & 380 & 25 & 0.53 & 0.40 \\
\hline D & 380 & 380 & 380 & 0.98 & 0.69 \\
\hline
\end{tabular}

than for a shorter flexible substituent material, i.e., polymer II. Thus, the reaction rate (i.e., viscosity) of polymer II is higher than that of polymer III.

Agarwal and Khakhar suggested that enhancement of the polymerization rate can be explained by mixing at the high shear rates, which may reduce local stoichiometric imbalances of the monomers. ${ }^{4}$ Therefore, to find out which of mixing or orientation is responsible for the molecular weight enhancement, the viscosity of a semi-rigid rod-like polymer was studied. The semi-rigid rod-like polymer was expected to show relatively pure effects of mixing on the viscosity. Polymer IV is a semirigid rod-like polymer; it has a flexible tetramethylene unit in the main chain. The viscosities of the polymer solution are shown in Figure 5, which does not show a signiffcant enhancement of the molecular weight. Therefore, the present work shows that the molecular orientation rather than mixing, is probably responsible for the high polymerization rates.

Another experiment, involving four different histories of shearing, was conducted, in which the overall strain, $\gamma=\int \dot{\gamma} \mathrm{d} t$, was the same (see Table I). Table 1 shows the evolution of the inherent viscosities of the polymers I and II with different shearing histories. In case of the polymer I, the gradual increase in a shear rate from $25 \mathrm{~s}^{-1}$ to $380 \mathrm{~s}^{-1}$ (A in Table I) gives a high molecular weight (inherent viscosity $=0.97$ ). The inherent viscosity obtained from shear rates of $25(1-5 \mathrm{~min}), 380(5-10$ $\mathrm{min})$, and $380 \mathrm{~s}^{-1}(10-15 \mathrm{~min})$ (B in Table I) is nearly the same (inherent viscosity $=0.98$ ). High initial and low final shear rates ( $\mathrm{C}$ in Table $\mathrm{I})$ give a low inherent viscosity value. The sample with only the high shear rate, i.e., $380 \mathrm{~cm}^{-1}$ (D in Table I), shows $0.98 \mathrm{dL} \mathrm{g}^{-1}$ as an inherent viscosity. Therefore, it can be concluded that it is the final shear rate that is important in molecular weight enhancement of the present system. Polymer II 
shows a similar trend (see Table I).

From the experimental results, the following mechanism can be proposed. The initial step of the polymerization $(\sim 10 \mathrm{~min})$, in which the reaction rate is relatively high, is controlled by a general reaction kinetics. The molecular orientation induced by shearing increases the rotational diffusivity even for rigid rod main chain polymers having stiff or bulky flexible substituents, and thus it increases the number of pairs of molecules which can react with each other. This results in an increase in the reaction rate.

\section{CONCLUSIONS}

The molecular weights of liquid crystalline polymers were increased by shearing during polymerization. A long flexible substituent on the phenylene group in the polymer main chain reduced the molecular weight enhancement, since it makes the molecular orientation difficult. The polymer, with a flexible spacer in the main chain, did not show a significant increase in molecular weight. This implies that the molecular orientation rather than mixing is the crucial factor for increasing the molecular weight of the final polymer.

Acknowledgment. This research was supported by Non-directed Research Fund, Korea Research Foundation, 1993.

\section{REFERENCES}

1. D. B. Cotts and G. C. Berry, Macromolecules, 14, 930 (1981).

2. B. Jingheng, Y. Anji, Z. Shengqing, Z. Shufan, and H. J. Chang, J. Appl. Polym. Sci., 26, 1211 (1981).

3. U. S. Agarwal and D. V. Khakhar, Nature, 360 (5), 53 (1992).

4. U. S. Agarwal and D. V. Khakhar, J. Chem. Phys., 96, 7125 (1992).

5. M. Doi and S. F. Edwards, J. Chem. Soc., Faraday Trans. 2, 74, 918 (1978).

6. P. W. Morgan, Macromolecules, 10, 1381 (1977).

7. M. Arpin and C. Strazielle, Polymer, 18, 591 (1977).

8. B.-W. Jo, J.-H. Chang, and J.-I. Jin, Polym. Eng. Sci., 35 (20), 1615 (1995).

9. N. J. Park, MSc. Dissertation, Hannam University, 1995.

10. M. Doi and S. F. Edwards, "The Theory of Polymer Dynamics," Clarendon Press, Oxford, 1986. 